\title{
Predictive Modeling of Arbitrary Loaded TMF Crack Growth in Superalloys
}

\author{
W. Steven Johnson ${ }^{1}$, Richard W. Neu ${ }^{1}$, Andrew T. Radzicki ${ }^{2}$, Benjamin S. Adair ${ }^{3}$, and Vincent M. Barker ${ }^{4}$. \\ ${ }^{I}$ Georgia Tech - Atlanta, GA (United States of America) \\ ${ }^{2}$ US Air Force - Colorado Springs, CO (United States of America) \\ ${ }^{3}$ Self employed - Oskaloosa, IA (United States of America) \\ ${ }^{4}$ Lockheed Martin - Marietta, GA (United States of America)
}

\begin{abstract}
Hot sections in turbine engines are subjected to large variations in temperatures and mechanical/thermal loadings. As such, accurate predictions of fatigue crack growth must account for many physical phenomena: temperature dependent crack growth behavior, load interaction history effects, time at temperature effects, temperature history effects, and the effects of stress/temperature/time on the materials. Through extensive experimental work on superalloys, a very definite "temperature history effect" on the resulting crack growth behavior has been identified and modeled. This work also identified a Temperature Affected Zone (TAZ) that occurs ahead of the crack tip and affects subsequent crack growth rates. The size of the TAZ is dependent on temperature, hold time, and stress state. Measurements of the TAZ were made under various conditions. The changes that occur in this TAZ are a combination of oxidation and material microstructure evolution. Various simplified "hot section" engine spectra (changing temperatures and stress levels) were tested to determine resulting crack growth behavior. Correlation between the experiments and model predictions were good and generally conservative.
\end{abstract}

\section{Introduction}

The world is dependent on jet turbine aircraft for travel and commerce. Although the technology is relatively mature, there are still unexpected failures as a recent high publicity engine failure highlighted: an American Airlines flight in Chicago, Illinois in 2017 [1]. Final reporting blamed an undetected manufacturing flaw in one of the alloy 718 turbine disks that grew by low cycle fatigue until catastrophic failure [1]. As shown in Figure 1 , the typical spectra turbine disks are exposed to are complex combinations of thermal and mechanical loading.

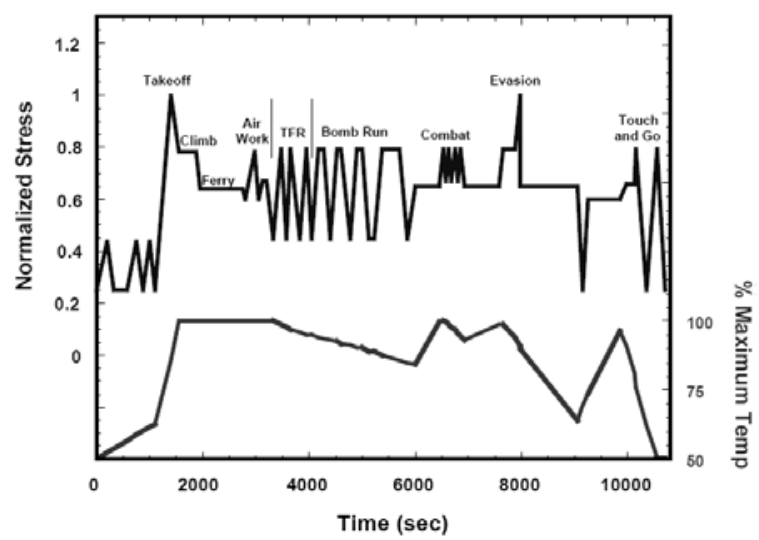

Fig. 1. Typical temperature and loading profile for military fighter aircraft high temperature rotor components [2]

Using a damage tolerant approach, where an initial flaw is assumed, predicting fatigue crack growth rate (FCGR) in these situations is especially difficult. The authors sought to develop a robust model for predicting crack growth in high temperature turbine engine alloys, specifically in nickel-base superalloys.

\subsection{Background}

Various studies have been undertaken to characterize the impact on FCGR of slow frequency loading at high temperature on Ni-base superalloys $[3,4,5,6]$. In these 
situations, the combination of time and high temperature allows for the material ahead of the crack tip to become weakened and leads to intergranular and faster subsequent crack growth [6].

Though not the only active mechanism contributing to accelerated FCGR, oxidation ahead of the crack tip plays a significant role. The high stress at the crack tip exacerbates oxidation penetration, but not necessarily in a uniform manner. Pfaendtner and McMahan showed that in an oxidizing environment, certain grain boundaries are more susceptible to embrittlement [7]. The crack will tend to propagate along these embrittled grain boundaries faster than the rest of the crack front. This was corroborated by Viskari et al. [8]. Additionally, Viskari et al. provided a schematic of how uneven oxidation at the crack tip will lead to an uneven crack front, shown in Figure 2.

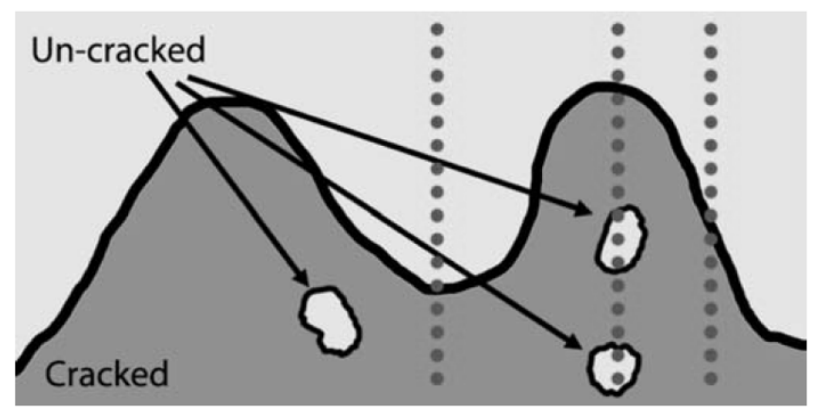

Fig. 2. Schematic of oxidation penetration at the crack tip leading to an uneven crack front and areas of uncracked material [8]

Work done on the depth of oxidation penetration at the crack tip by Miller et al. characterized how far ahead of the crack tip oxidation penetrated. They conducted a time-dependent crack growth test at $700^{\circ} \mathrm{C}$ and used $\mathrm{X}$-ray photoelectron spectroscopy to analyze how far ahead of the crack tip oxidation had penetrated and showed an oxidation affected region extending $150 \mu \mathrm{m}$ ahead of the crack tip [9].

The concept of an area of material ahead of a crack tip, termed "damage zone" or "thermally affected zone," weakened by exposure to time spent at elevated temperature in a FCG situation for IN 718 has been explored by several authors $[10,11,12,13,14]$. In their work, the specific contributions of the different crack growth mechanisms (oxidation, creep, materials evolution, etc.) are not assigned, only the net result on the FCGR is taken into consideration.

It is important to note that though several of these authors use the term "damage zone," to avoid confusion with the concept of fatigue damage or plastically induced damage, the terminology of "temperature affected zone (TAZ)" was utilized for this effort. The concept states that while a crack is propagating through this TAZ, an increased FCGR will occur. Once the crack grows through the TAZ, the FCGR will return to the expected FCGR had no exposure to time at elevated temperature occurred. The authors use the term TAZ to indicate that the effect of time at temperature on crack growth is separated from the "normal" crack growth damage that occurs due to cyclic loading.

Work done by Storgards et al. showed that a crack propagating through this TAZ will have an intergranular appearance [14]. This intergranular appearance is similar to that for a low frequency, high temperature, and air environment situation [6]. This indicates that weakening of the grain boundaries plays a significant role in the effect of the thermally affected zone on FCGR. Along with areas of intergranular failure, areas of transgranular crack propagation are also present indicating that the area ahead of the crack tip is not fully dominated by one mechanism. Areas ahead of the crack tip not significantly weakened by exposure to time at high temperature (transgranular appearance) are left to hold back the crack tip when cycling resumes as the weakened material (intergranular appearance) puts up less resistance. Of course, whether the intergranular cracking happens depends upon the temperature, hold time, and material. Lundstrom et al. showed that for a specimen subject to fully time-dependent crack growth at $650^{\circ} \mathrm{C}$, and then subsequently cycled, an increase in FCGR on the order of three-hundred times as fast is experienced [13].

\section{Experimental Work}

Robust experimental studies were undertaken to characterize the impact of spectrum loading on Ni-base superalloys. The effect of previous mechanical overand under-loading was accomplished by Barker et. al. and Adair et. al. [10, 15]. Additionally, the depth of oxidation penetration at the crack tip for compressive and tensile holds of varying temperature, hold duration, and stress intensity at the crack tip was explored [16]. This paper focus on the latter experimental study.

\subsection{Material Description}

Studies were conducted on the powder metallurgy Ni-base superalloy Inconel 718, a polycrystalline alloy commonly used for turbine engine applications up to $650^{\circ} \mathrm{C}$. Inconel 718 is primarily strengthened through precipitate hardening. As with other Ni-base superalloys, it is primarily strengthened by $\gamma$ " and $\gamma^{\prime}$ phases in a $\gamma$ matrix [17]. The material showed no preferred grain orientation and had an average grain diameter of $4 \mu \mathrm{m}$. Additionally, the IN 718 exhibited a primarily intergranular distribution of globular $\delta$ precipitates. The nominal chemical composition of powder metallurgy IN 718 is shown in Table 1.

Table 1. Nominal chemical composition (wt. \%) of powder metallurgy IN 718 [18]

\begin{tabular}{|c|c|c|c|c|c|c|c|c|}
\hline & Ni & $\mathbf{C r}$ & $\mathbf{F e}$ & $\mathbf{N b}$ & $\mathbf{M o}$ & $\mathbf{V}$ & $\mathbf{T i}$ & $\mathbf{C}$ \\
\hline $\mathbf{I N}$ & Bal. & 18.6 & 18.5 & 5.0 & 3.1 & 0.9 & 0.4 & 0.04 \\
$\mathbf{7 1 8}$ & & & & & & & & \\
\hline
\end{tabular}


The material for this study came in the form of a forged turbine disks heat treated in a typical manner for a turbine disk application. The turbine disks were provided by the Pratt and Whitney- United Technologies Corporation. Single Edge Notched Tension (SENT) specimens were machined from the forged turbine disks such that the loading direction on the specimen was in the radial direction on the disk as shown in Figure 3.

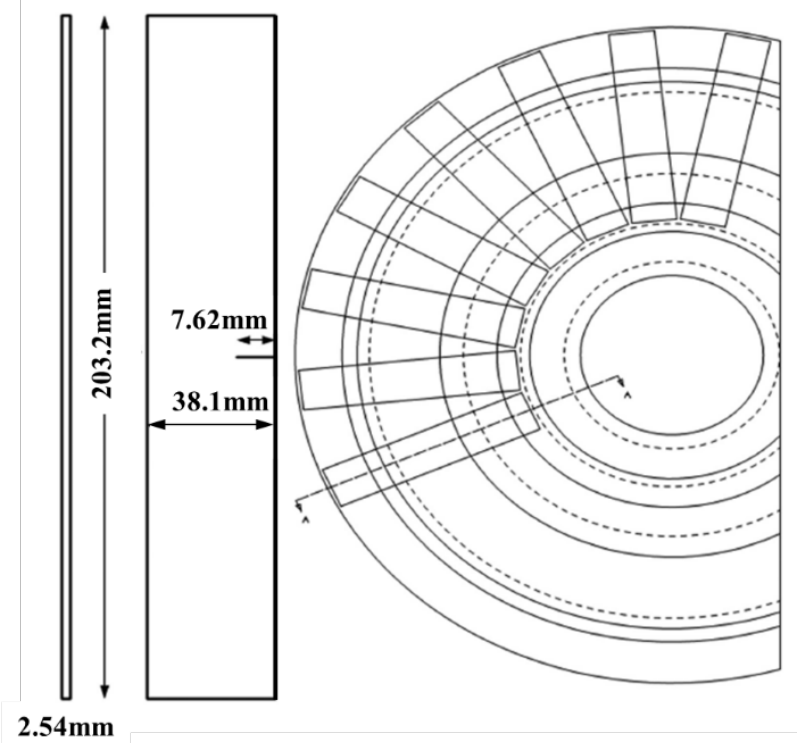

Fig. 3. Specimen geometry and the orientation they were machined from the turbine disk

Load controlled fatigue crack growth tests were conducted in accordance with ASTM Standard E647 utilizing an $89 \mathrm{kN}$ servo-hydraulic load frame utilizing a TestStar IIs controller and water cooled wedge grips [19]. The specimens were heated with a $3.5 \mathrm{~kW}$ induction heater.

Cracks were measured both optically using a Questar QM-100 long distance microscope for all tests and using the direct current electric potential difference (EPD) method described in ASTM Standard E647 [19] for several test points. Power for the EPD crack measurements was proved by a Sorensen SRL10-25 power supply at a constant 5 amps. The signal was amplified with an Omni-Amp III set to $1000 \mathrm{x}$ and recorded with the TestStar IIs. The induction heater induced significant noise in the EPD signal, so readings for crack length were only taken utilizing the EPD system with the induction heater turned completely off (i.e. at room temperature). The EPD voltage signal was converted to crack length using HH Johnson's equation [20].

\subsection{Thermomechanical Spectra}

Several different spectra were designed to isolate the effect of time spent at elevated temperature. First, simple isothermal loading spectra were designed based on the work of Liu et al. to isolate the effects of hold duration, hold temperature, and hold stress intensity on the development of a TAZ and its effect on FCGR [12]. Similar creep-fatigue spectra, such as that used by Gustafsson et al. do not specifically isolate the effect of a single tensile hold at high temperature [11]. To isolate the impact of a single high temperature hold on the development of a TAZ, a test series including tensile holds at three temperatures: $550^{\circ} \mathrm{C}, 600^{\circ} \mathrm{C}$, and $650{ }^{\circ} \mathrm{C}$, five hold durations: 30 seconds, 90 seconds, 300 seconds, 3600 seconds, and $>15000$ seconds, and three hold stress intensities: $25 \mathrm{MPa} \sqrt{ } \mathrm{m}, 35 \mathrm{MPa} \sqrt{\mathrm{m}}$, and 45 $\mathrm{MPa} \sqrt{\mathrm{m}}$ was designed. These tests involved 1) cyclically growing the crack at least $0.25 \mathrm{~mm}(\mathrm{R}=0.05)$ at low stress intensities (on the order of 9 MPA $\sqrt{ }$ ) to minimize effects of loading history on the tensile hold (the temperature for cycling was either $260^{\circ} \mathrm{C}$ (optical measurement) or room temperature (EPD crack measurement)), 2) executing the tensile hold at high temperature, and 3) cyclically growing the crack until it grew through the TAZ $(\mathrm{R}=0.5)$ as shown in Figure 4 . Thirty six tests were completed as shown in Table 2 below.

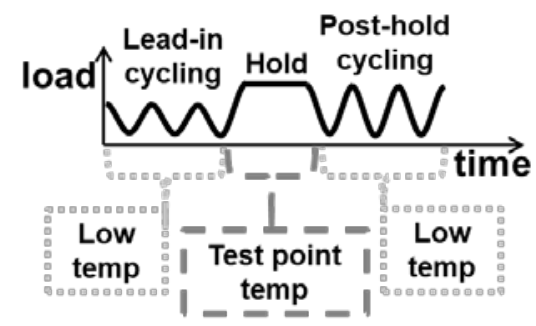

Fig. 4. Single TAZ experimental spectrum

Table 2. Isolated TAZ test matrix

\begin{tabular}{|c|c|c|}
\hline $\begin{array}{c}\text { Stress } \\
\text { Intensity of } \\
\text { Hold } \\
\left(\mathbf{M P a}{ }_{\mathbf{m})}\right.\end{array}$ & $\begin{array}{c}\text { Hold } \\
\text { Temp } \\
\left({ }^{\circ} \mathbf{C}\right)\end{array}$ & $\begin{array}{c}\text { Hold Duration } \\
\text { (sec) }\end{array}$ \\
\hline \multirow{3}{*}{25} & 550 & $90,300,3600,18200$ \\
\cline { 2 - 3 } & 600 & $30,90,300,3600$ \\
\cline { 2 - 3 } & 650 & $30,90,300,3600$ \\
\hline \multirow{3}{*}{35} & 550 & $90,300,3600,18200$ \\
\cline { 2 - 3 } & 600 & $30,90,300,3600$ \\
\cline { 2 - 3 } & 650 & $30,90,300,3600$ \\
\hline \multirow{3}{*}{45} & 550 & $90,300,3600,15675$ \\
\cline { 2 - 3 } & 600 & $30,90,300,3600$ \\
\cline { 2 - 3 } & 650 & $30,90,300,3600$ \\
\hline
\end{tabular}

Additionally, to better capture spectrum loading history effects, several spectra were developed. First, isothermal test points at $650^{\circ} \mathrm{C}$ were executed with holds at $0 \%, 25 \%, 50 \%, 75 \%$, and $100 \%$ of the maximum cyclic load $(\mathrm{R}=0.05)$. Second, out-of-phase (OP) thermomechnical fatigue (TMF) spectra with tensile holds at $50 \%$ of the cyclic maximum load were designed to highlight the effect of increasing or decreasing load leading into the tensile hold. Figure 5 shows both spectra. 


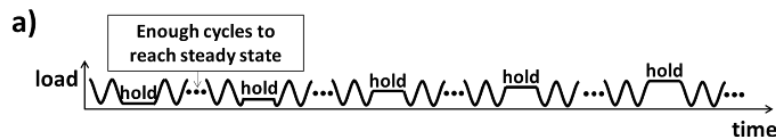

b)

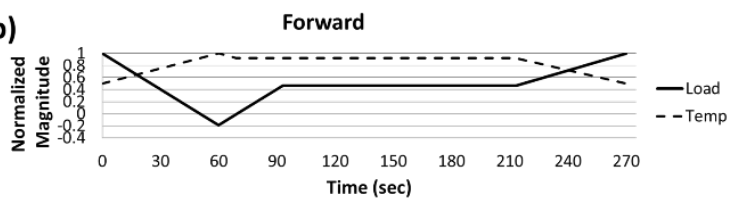

Backward

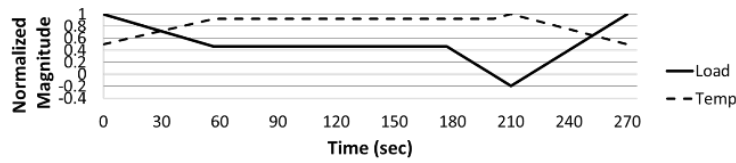

Fig. 5. Spectra to isolate spectra effects on TAZ: a) isothermal with intermittently imposed tensile holds b) OP TMF spectra

In addition to more fundamental TMF spectra used to characterize TAZ development and sequence effects, several different representative TMF aircraft spectra were developed with maximum temperatures of $650^{\circ} \mathrm{C}$. Tested representative fighter and transport spectra are shown in Figure 6. Additionally, a spectrum developed by an aircraft engine consortium was tested and is shown in Figure 7 and included a compressive high temperature hold.
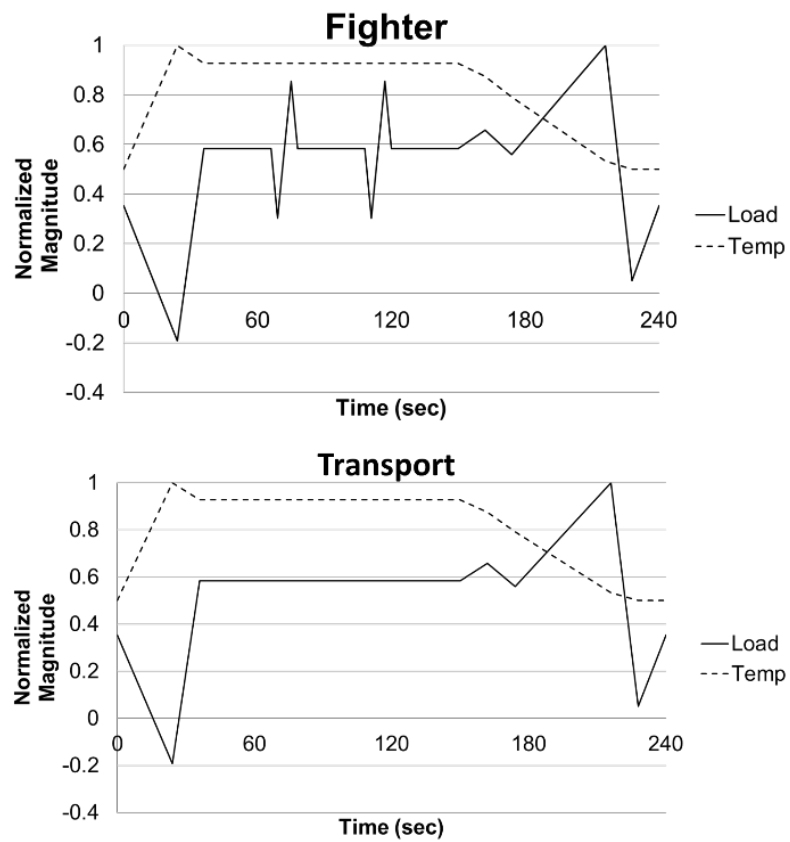

Fig. 6. Aircraft TMF spectra

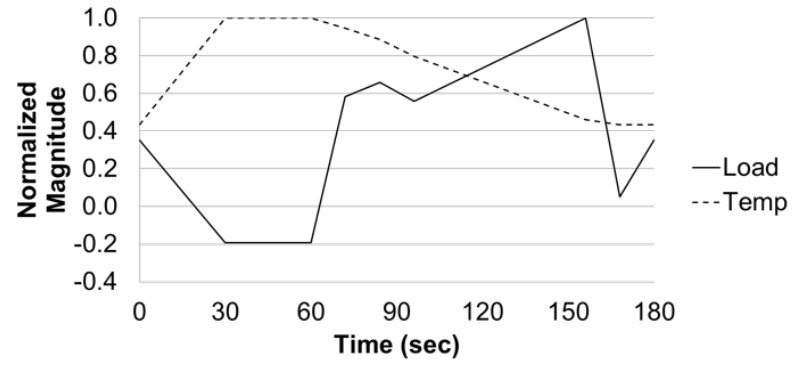

Fig. 7. Engine consortium developed TMF spectrum

\section{Experimental Results}

\subsection{TAZ Fractography}

Single tensile holds at the maximum cyclic load resulted in clearly visible change to the fracture surface. Fractographic investigation of the failure surface identified the characteristics of the TAZ as shown in Figure 8. It shows primarily transgranular crack propagation while the specimen was cycled at low temperature, as expected. The area ahead of the crack tip immediately following the hold however shows areas of intergranular as well as transgranular crack propagation. This agrees with the work of Storgärds et al. [21]. Additionally, secondary cracking was observed extending parallel to the crack growth direction. Another significant characteristic of the TAZ is that it extends further ahead of the crack tip in the center of the specimen (plane strain dominated) compared to the edges of the specimen (plane stress dominated). This indicates that it is more conducive for the TAZ to develop in an area of higher hydrostatic stress (plane strain). This higher level of stress strains the grain boundaries allowing oxygen to penetrate further than on the free surface. 


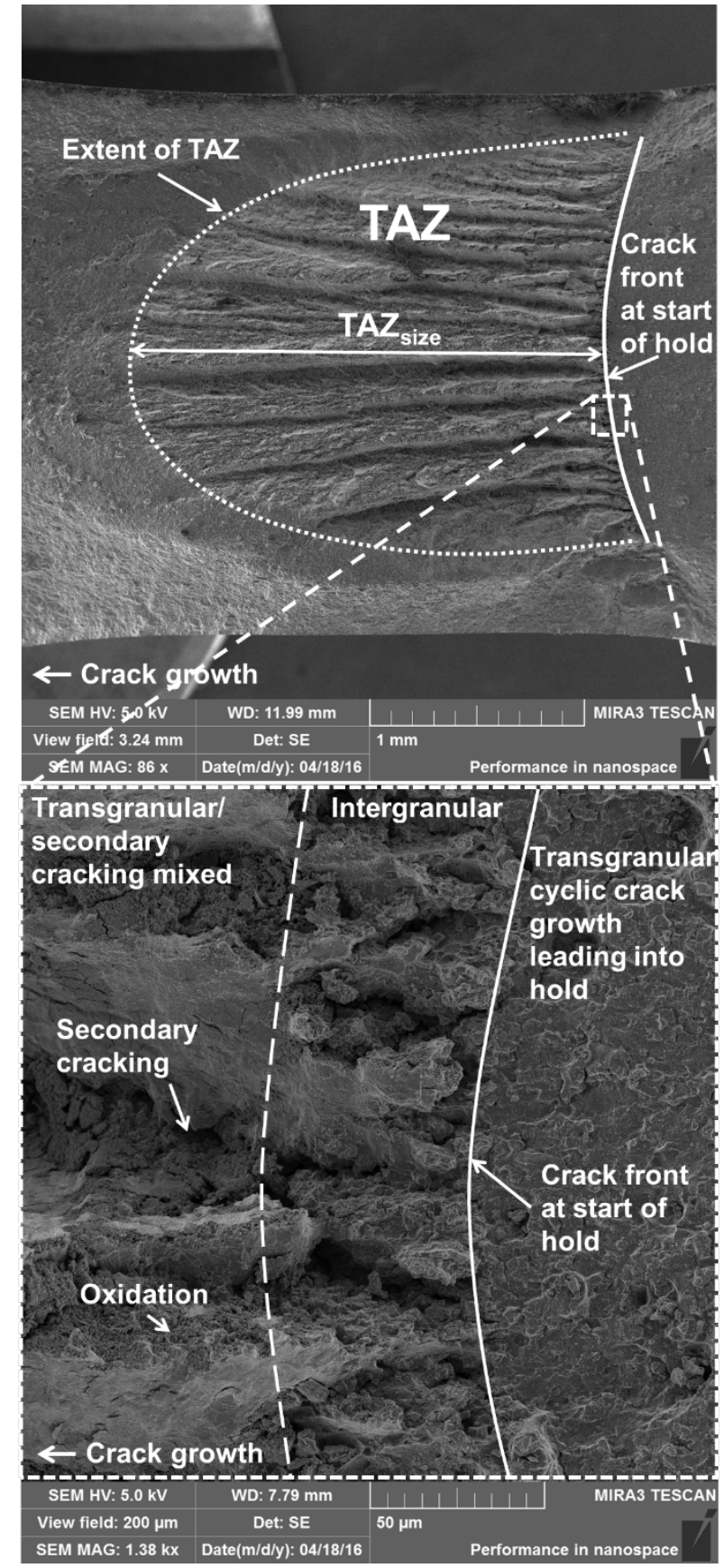

Fig. 8. $\mathrm{TAZ}$ appearance for $\mathrm{K}_{\text {hold }}=45 \mathrm{MPa} \sqrt{\mathrm{m}}$, Temp $=650^{\circ} \mathrm{C}$ and hold duration $=3600 \mathrm{sec}$

To some extent, these characteristics were present on the failure surface for all test points identified in Table 2 . A qualitative comparison of the crack surface morphology for the test points is shown in Figure 9. As the stress intensity of hold, temperature of hold, and/or the duration of hold increases, the crack morphology transitions from one showing limited effects of weakening of the material ahead of the crack tip to one showing increased intergranular cracking, secondary cracking, and oxidation.
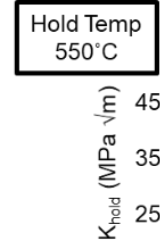

हิ 45

$\sum^{\pi / 2} 35$

끙 25

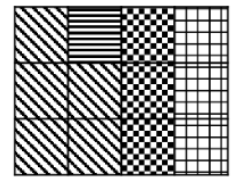

$903003600>15000$

Hold Duration (sec)
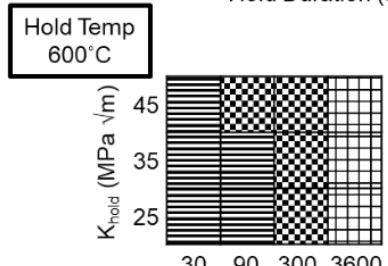

$\begin{array}{llll}30 & 90 & 300 & 3600\end{array}$
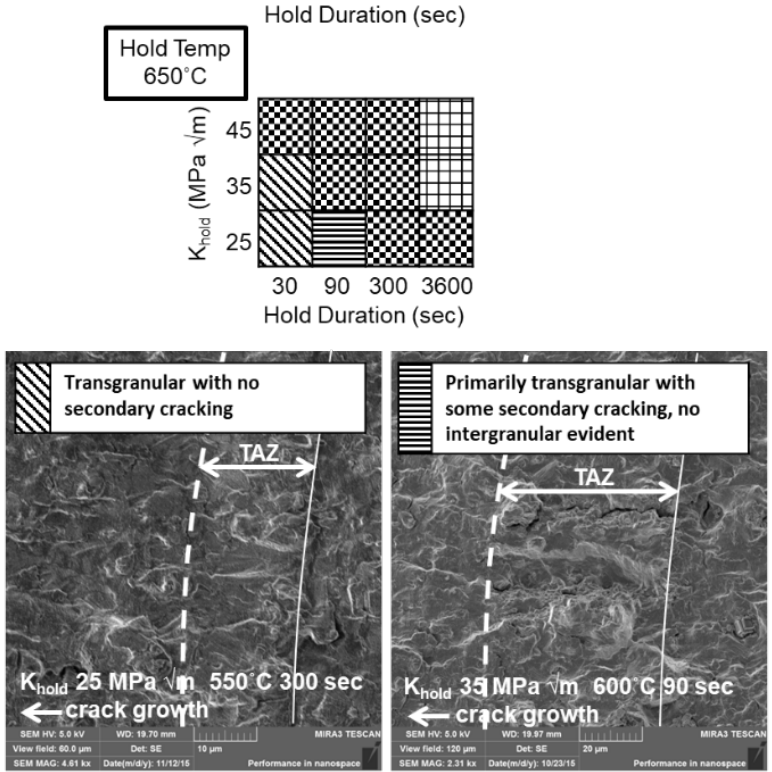

Some mixed mode, secondary
cracking, intergranluar evident, some oxidation

$$
\text { I TAZ }
$$
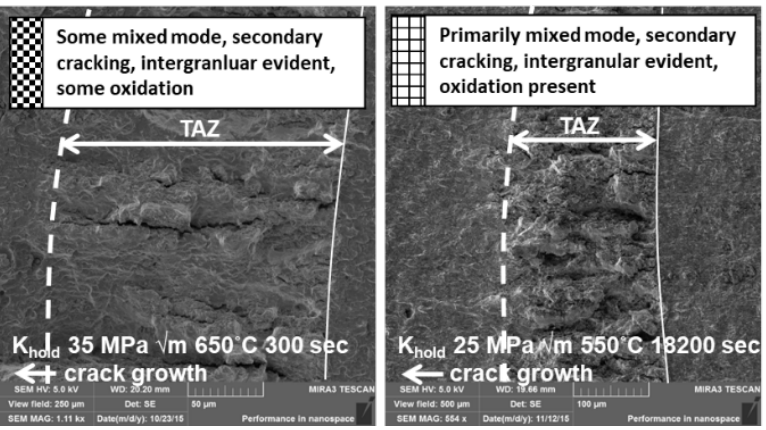

Fig. 9. Qualitative characteristics of the TAZ

\subsection{TAZ Size Empirical Fit}

To quantitatively characterize TAZ size, the depth of damaged material was measured at the center of the specimen as shown in Figure 8. Across the test points shown in Table 2, the TAZ size showed a power-law relationship as the tensile hold stress intensity, duration, and temperature were changed. Additionally, as diffusion of oxygen is a significant contributor to TAZ development, an Arrhenius type equation was used to fit TAZ development. The equation used to model TAZ size is given by: 


$$
T A Z_{\text {size }}=C t^{n_{1}} K_{\text {hold }}{ }^{n_{2}} e^{n_{3} \frac{-Q}{R T}}
$$

where $\mathrm{TAZ}_{\text {size }}$ is in $\mathrm{mm}$, $\mathrm{t}$ is the hold duration in seconds, $K_{\text {hold }}$ is the stress intensity of the hold in MPA $\sqrt{ }$, T is the temperature of hold in Kelvin, and R is the universal gas constant. Work by Chang showed the activation energy for high temperature oxidation of Ni-base superalloys as $25500 \mathrm{~J} / \mathrm{mol}$ and was used for this model [22]. Regression analysis was used to determine the parameters $\mathrm{C}, \mathrm{n}_{1}, \mathrm{n}_{2}$, and $\mathrm{n}_{3}$. Table 3 shows the parameters used in this model.

Table 3. $T A Z_{\text {size }}$ calculation parameters

\begin{tabular}{|l|l|l|}
\hline $\mathrm{C}$ & 0.291 & $(\mathrm{sec})^{-n_{1}}(\mathrm{MPa} \sqrt{\mathrm{m}})^{-n_{2}}$ \\
\hline $\mathrm{n}_{1}$ & 0.48 & \\
\hline $\mathrm{n}_{2}$ & 2.6 & \\
\hline $\mathrm{n}_{3}$ & 0.38 & \\
\hline $\mathrm{Q}$ & 255000 & $\mathrm{~J} / \mathrm{mol}$ \\
\hline $\mathrm{R}$ & 8.31446 & $\mathrm{~J} / \mathrm{mol} \mathrm{K}$ \\
\hline
\end{tabular}

\subsection{Impact of TAZ on FCGR}

Initially, crack length measurements were collected only optically, however, as is evident in Figure 8, the TAZ does not reach the free surface of the specimen, and as this is where the optical method measures the crack length, no impact of FCGR was observed. Due to limited specimens available, only three test points were re-accomplished using both the optical method of crack length measurement as well as the EPD method. The FCGR data for these test points indicated that the crack growth rate does accelerate while it is growing through the TAZ as shown in Figure 10.

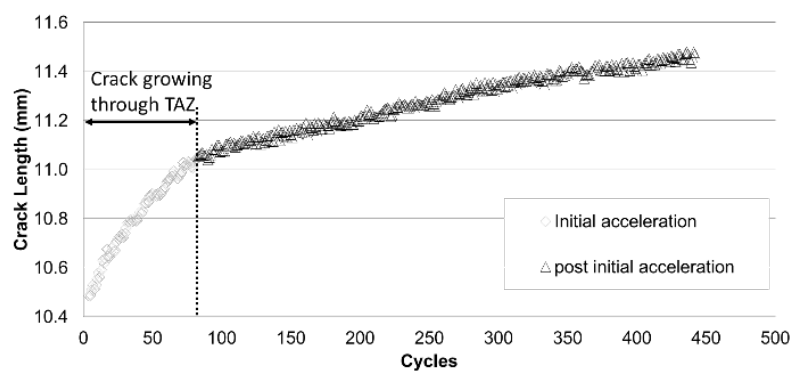

Fig. 10. Crack growth acceleration immediately following tensile hold at $\mathrm{K}_{\text {hold }} 45 \mathrm{MPA} \sqrt{\mathrm{m}}$, hold duration $=3600 \mathrm{sec}$, hold temperature $=650^{\circ} \mathrm{C}$

This increase in FCGR due to a TAZ was on the order of three to five times faster, not the three hundred times increase observed by Lundstrom et al. [13]. This acceleration more closely corresponds to the work of Barker et al. who observed four times increase in FCGR [10]. A TAZ acceleration factor (TAF) was developed to characterize the accelerating effect of the TAZ. The $\mathrm{TAF}$ is a multiplication factor on the crack growth rate and takes the form:

$$
T A F=1+D\left(\frac{T A Z_{\text {size }} \text { current }}{r_{p}}\right)^{p}
$$

where $\mathrm{TAZ}_{\text {sizecurrent }}$ is the current $\mathrm{TAZ}$ size in $\mathrm{mm}, \mathrm{r}_{\mathrm{p}}$ is the plastic zone size in $\mathrm{mm}$ (based on plane stress/strain calculation in the model), and D and $\mathrm{p}$ are fitting parameters where $\mathrm{D}=6.0$ and $\mathrm{p}=0.5$. The measured FCGR accelerations due to TAZ showed a good correlation as shown in Figure 11.

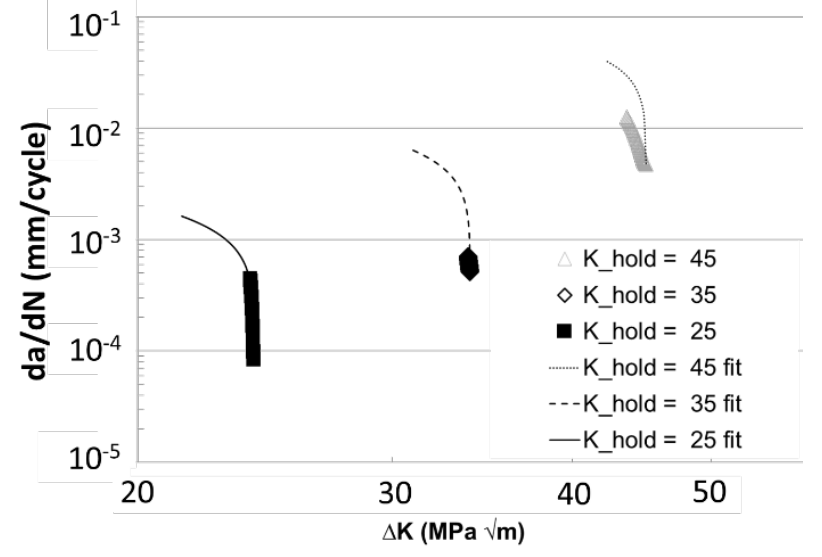

Fig. 11. TAZ impact on crack growth rate using equation (2)

\subsection{Spectrum Effects on TAZ Development}

Utilizing isothermal and TMF spectra as shown in Figure 5 and Figure 7, the impact of spectrum history on TAZ development was also characterized. Using the consortium spectrum, shown in Figure 7, compressive holds at elevated temperature were shown to have no accelerating effect on FCGR [23]. Additionally, using the isothermal spectrum, shown in Figure 5, tensile holds at $75 \%$ of the prior cyclic maximum load or less did not show development of a TAZ. This effect corresponds to the work of Ponnelle et al. [24].

The OP TMF spectra, shown in Figure 5, revealed the progression of loading (increasing or decreasing) leading into a tensile hold will determine if a high temperature tensile hold will develop a TAZ. If the load is increasing leading into a hold, the "forward" spectrum, a TAZ was observed to develop. Correspondingly, if the load is decreasing leading into a hold, the "backward" spectrum, a TAZ was not observed to develop.

\section{FCG Modeling}

\subsection{Assumptions and Algorithm}

Modeling of the TAZ's effect on FCGR was incorporated into a linear elastic fracture mechanics based crack growth model originally developed by Johnson, the Multi-Parameter Yield Zone model [25]. His isothermal model effectively accounted for the impact of previous over- and under-loading on subsequent fatigue crack growth. To expand this model to the thermomechanical spectra of rotor alloys, Baker et al. and Adair et al. completed an experimental study to 
characterize how mechanical over- and under-loads affect FCG when temperature is varying and incorporated their results to create the MPYZThermomechanical Fatigue (MPYZ-TMF) model [10, $15]$.

The MPYZ-TMF model uses the stress intensity solutions for several common test specimen geometries. The user provides temperature dependent material properties, including: yield strength, fracture toughness, and crack growth rate parameters for either a Paris or Forman crack growth law with properties at intermediate temperatures being linearly interpolated. Additionally, load interaction and TAZ parameters are also provided by the user.

Experimental data suggests that TAZ develops when the crack is open at elevated temperatures [16]. Additionally, a general downward trend in loading will mitigate TAZ development. To account for these characteristics in the model, TAZ was only allowed to develop when:

1. Segment temperature is above $500^{\circ} \mathrm{C}$ (selected based on work of James et al. who showed negative effect of time at temp down to $538^{\circ} \mathrm{C}$ and Sadananda and Shahinian who showed no effect at $425^{\circ} \mathrm{C}$ and below [26, 27].

2. Stress intensity is greater than or equal to zero

3. Stress intensity is greater than or equal to $75 \%$ of any of the three previous segments.

Additionally, it is feasible that segments of a realistic spectrum may traverse these limits. To ensure TAZ is calculated to develop during portions of such segments, each segment was partitioned into 5 sections. With experimental data for the TAZ developed for high temperature hold durations from 30 to 18200 seconds, partitioning into too many sections could take the TAZ development calculation outside the range of the empirical TAZ data [16]. The use of five sections was a good balance between fidelity and computational efficiency. Figure 12 shows the sample fighter aircraft spectra from Figure 6 highlighting the portions where the model predicts TAZ will develop.

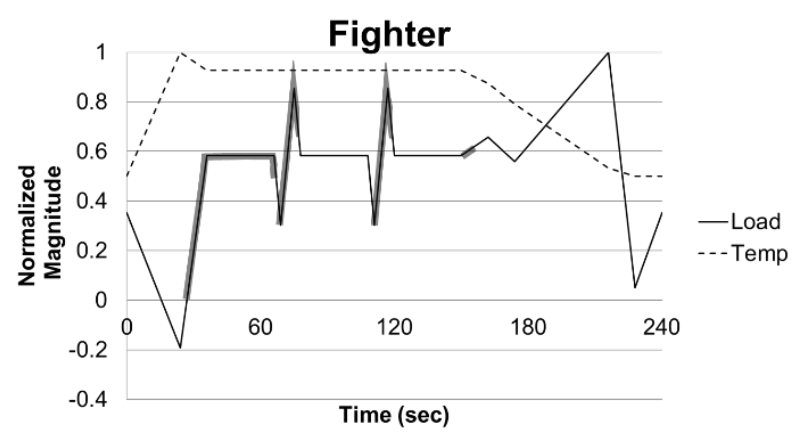

Fig. 12. Fighter aircraft spectra highlighting where the model predicts TAZ will develop

Since oxidation is a primary contributor to TAZ development, an equation similar to the parabolic oxygen diffusion law used by Ghonem et al. was used in the model to limit the addition of a new section's TAZ to existing TAZ [6]. TAZ portions are summed using:

$$
T A Z_{\text {size }_{\text {newtotal }}}=T A Z_{\text {size }_{\text {existing }}}+\frac{T A Z_{\text {size }} \text { newsegment }}{\left(T A Z_{\text {size }} \text { existing }+1\right)^{T A C}}
$$

where $\mathrm{TAZ}_{\text {size }}$ is in $\mathrm{mm}$ and the TAC is the TAZ accumulation coefficient (TAC) and was chosen as 2.0. This forces the contribution of new TAZ to diminish when a significant TAZ is already present and the trend is shown in Figure 13.

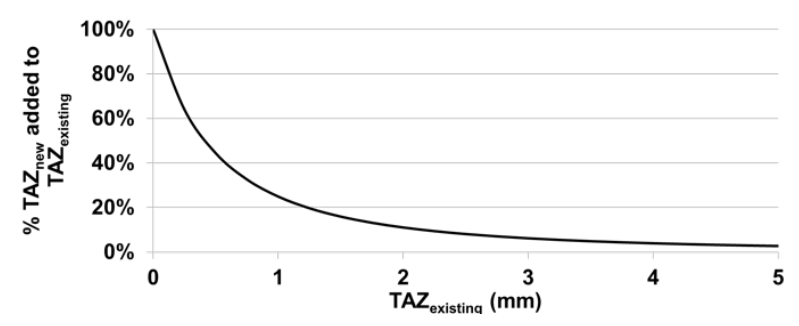

Fig. 13. Percentage of new TAZ that contributes to existing TAZ

One significant limitation of the MPYZ and the first iteration of the MPYZ-TMF model was its inability to account for complex TMF spectra such as that shown in Figure 1 without first simplifying by some method such as rainflow counting. To be able to account for such spectra, the current version of the model calculates crack growth load segment by load segment where crack propagation is only allowed to occur on segments with increasing stress intensity. The average temperature for the segment used for calculating crack growth. This also allows for the easy incorporation of TAZ development described earlier.

\subsection{Predictions}

For isothermal loading, the model predicts conservative results as shown in Figure 14. The model predicted more conservative results for fast frequency loading, where TAZ effects are not expected to impact FCGR, compared to slower loading which more closely matches experimental data, though is still conservative.

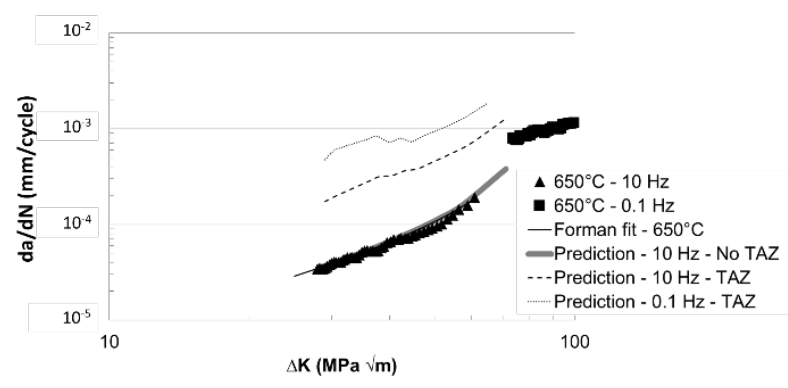

Fig. 14. MPYZ-TMF predictions for $650^{\circ} \mathrm{C}$ isothermal cyclic loading with and without TAZ effects compared to experimental data and Forman crack growth equation fit

The model predicted good results for the representative aircraft spectra as shown in Figure 15. In 
this case, the model also accurately predicts large TAZ development for the transport spectrum but a longer overall life because of the lack of significant subcycles to grow the crack as in the fighter spectrum.

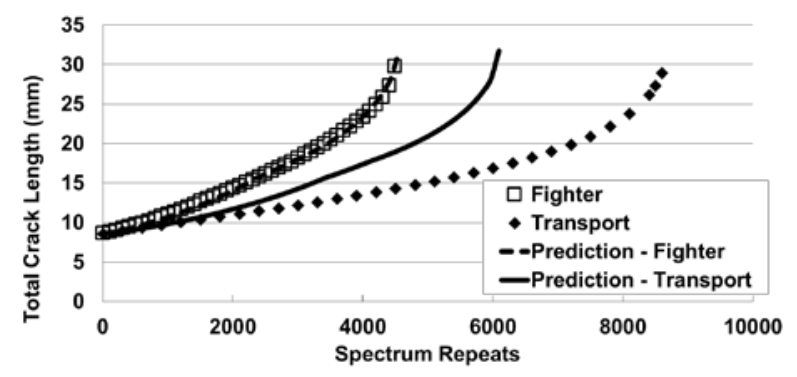

Fig. 15. MPYZ-TMF prediction - fighter and transport spectra

The model was also used to predict crack growth for a cylindrical specimen geometry as shown in Figure 16. Two strain-controlled tests were conducted using the consortium spectrum shown in Figure 7 with a hollow cylindrical IN 718 specimen with starter hole. The model predicted goods results and highlights the ability of the model to accommodate various specimen geometries.

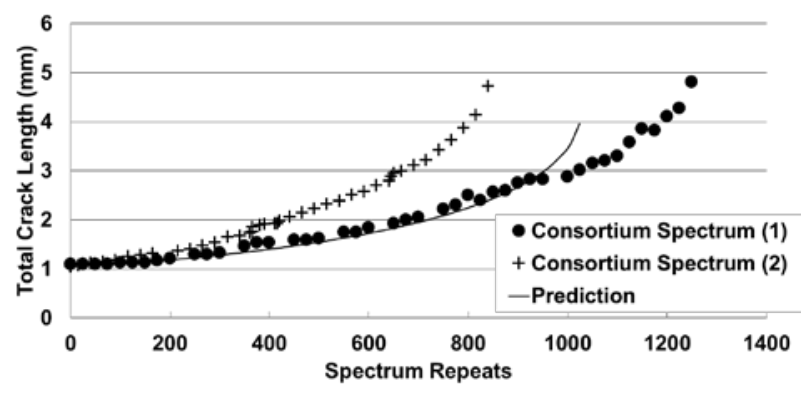

Fig. 16. Engine consortium experimental data and MPYZ-TMF prediction for hollow cylindrical specimen

\section{Conclusions}

The accelerating effect of time spent at elevated temperature in aircraft turbine disk spectra significantly affects the life of the component. The model developed provides a capability to account for the impact of previous over- and under-loads and the detrimental effect of time spent at elevated temperature without simplification of the spectra. Further, the unique approach of segmenting the TMF spectra to allow for the effects of time spent at elevated temperature to be incorporated matched well to experimentally observed trends. Aircraft operators depend on accurate modeling of crack growth and this model will serve to save costs in the form of better defined inspection intervals and removal from service decisions and improved safety.

\section{References}

1. National Transporation Safety Board, NTSB/AAR18/01 (2018)

2. J. M. Larsen, A. H. Rosenberger, G. A. Hartman, S.
M. Russ, R. John, Tech. Rep. ADP014134, AFRL (2003)

3. T. Nicholas, T. Weerasooriya, N. E. Ashbaugh, Fract. Mech. 16th symp., ASTM STP 868, 167-180 (1985)

4. T. Weerasooriya, S. Venkataraman, Effects of load and thermal histories on mechanical behavior of materials (1987)

5. A. Pineau, Subcritical Crack Growth Due Fatigue, Corrosion and Creep, 483-530 (1981)

6. H. Ghonem, D. Zheng, Mat Sci and Engr: A, 150,151-160 (1992)

7. J. A. Pfaendtner, C. J. McMahon Jr, Acta Mater., 49, 3369-3377 (2001)

8. L. Viskari, S. Johansson, K. Stiller, Materials at High Temperatures, 28, 336-341 (2011)

9. C. F. Miller, G. W. Simmons, R. P. Wei, Scripta Mater., 44, 2405-2410 (2001)

10. V. Barker, W.S. Johnson, B. Adair, S. Antolovich, A. Staroselsky, Int. J. Fatigue, 52, 95-105 (2013)

11. D. Gustafsson, J. Moverare, K. Simonsson, S. Johansson, M. Hörnqvist, T. Månsson, S. Sjöström, Procedia Eng., 10, 2821-2826 (2011)

12. X. B. Liu, L. Z. Ma, K. M. Chang, E. Barbero, Acta Metall. Sin., 18, 55-64 (2005)

13. E. Lundström, K. Simonsson, D. Gustafsson, T. Månsson, Eng. Fract. Mech., 118, 17-30 (2014)

14. E. Storgärds, K. Simonsson, S. Sjöström, J. Moverare, J. Eng. Gas Turb. Power, 138, 012503 (2016)

15. B. Adair, W. Johnson, S. Antolovich, A. Staroselsky, Fatigue Fract. Eng. Mater. Struct., 36, 217-227 (2013)

16. A. Radzicki, PhD Dissert., GA Inst Tech, (2016)

17. J. Radavich, Superalloy 718--Metallurgy and Applications, (1989)

18. G. Gessinger, Powder Metallurgy of Superalloys: Butterworths Monographs Matrls, Elsevier, 2013.

19. ASTM Standard, E647-13AE1, (2013)

20. H. Johnson, Materials Research and Standards, 5, 442-445 (1965)

21. E. Storgärds, K. Simonsson, Experimental Mechanics, 55, 559-568 (2015)

22. K. Chang, GE-CRD 89CRD116 (1989)

23. A. Radzicki, W. Johnson, R. Neu, B. Annigeri, B. Ziegler, Fatigue Fract. Eng. Mater. Struct., 40, 1406-1415 (2017)

24. S. Ponnelle, B. Brethes, A. Pineau, European Structural Integrity Society, 29, 257-266 (2002)

25. W. S. Johnson, ASTM STP 748, 85-102 (1981)

26. L. James, Eng. Fract. Mech., 25, 305-314 (1986)

27. K. Sadananda, P. Shahinian, Creep-FatigueEnvironment Interactions, 86-111 (1979)

28. E. Andrieu, R. Molins, H. Ghonem, A. Pineau, 
Mat. Sci. Eng. A, 154, 21-28 (1992) 